DOI: $10.17805 / z p u .2015 .2 .38$

\title{
Фразеология как средство создания образа персонажа в драматургии А. В. Сухово-Кобылина
}

\author{
Т. В. ЛЕВИНОВА
}

(МОРДОВСКИЙ ГОСУДАРСТВЕННЫЙ УНИВЕРСИТЕТ ИМ. Н. П. ОГАРЕВА)

Фразеология является важнейшим средством связи человека с окружающей действительностью, при этом фразеологические единицы выполняют роль социокодов. Кроме того, в художественном произведении фразеология является отражением авторского мировидения и авторской стратегии. Жанр произведения существенно влияет на выбор инструментов, с помощью которых создается текст. Так, жанр драмы позволяет выявить большой пласт фразеологических единиц, выполняющих различные функции в тексте.

Одной из главных функций фразеологии является создание речевой характеристики, а также образа персонажа в целом. Значительное число таких единиц находим в драматургии А. В. Сухово-Кобылина. Целью данного исследования стал анализ фразеологии в речи четырех персонажей драм «Свадьба Кречинского», «Дело» и “Смерть Тарелкина». Примечательно, что по сюжету все герои являются чиновниками. Найденные фразеологические единицы преимущественно имеют негативный денотат и указывают на отрицательные стороны в характере персонажей: жажду наживы, расчетливость, бессердечность, жестокость, глупость, желание безраздельной власти. Драматург обличает чиновников и всю систему судопроизводства России XIX в., а фразеологизмы становятся символом беззакония государственной власти.

Высокий эмоциональный потенциал индивидуально-авторских трансформаций традиционных фразеологизмов воспринимается не только как средство обличения чиновников и всей системы судопроизводства, но и как переживание личного трагического опыта столкновения с этой системой. Изучение фразеологии позволяет выявить специфику 
языка художественного произведения, более точно представить характеры, а также обозначить способы передачи авторской установки, в частности, в изображении гротеска.

Ключевые слова: фразеология, фразеологические единицы, речевая характеристика, образ персонажа, авторская стратегия, русская драматургия, А. В. Сухово-Кобылин.

\section{ВВЕАЕНИЕ}

$\Phi^{\mathrm{s}}$ разеология является самым ярким средством вербализации представлений о физической, интеллектуальной, нравственно-этической, эмоциональной, этнической, социальной и др. оценке, которую дает человек себе и окружающему его миру. Так, по мнению Н. А. Завьяловой, «анализируя ФЕ (фразеологические единицы. T. А.), мы описываем повседневность. Повседневность - это дискурс, наполненный социокультурными смыслами (навыками, умениями, пониманиями, знаниями), отраженными в партиципациях (экзистенциальных природнениях - включениях, соучастиях, сопричастностях) и зафиксированными во фразеологии, описывающими реальность из будничных событий» (Завьялова, 2014: 197). Эти социокультурные знаки и составляют предмет фразеологии.

Особая роль отводится фразеологическим единицам, выполняющим кумулятивную функцию, в текстах художественной литературы. Именно они становятся сигналами авторских интенций, создают определенную картину мира как одно из средств реализации нарративных стратегий писателя. Кроме того, они организуют семантическое пространство текста и заостряют внимание читателя на важных деталях. Сошлемся здесь на мнение М. А. Фокиной: «Фразеологизмы относятся к числу активных средств создания авторской позиции, формирования повествовательной точки зрения и способствуют успешному декодированию авторского замысла, так как передают доминантные текстовые смыслы, репрезентируют концептуальное содержание художественного текста, транслируют специфические черты языковой личности писателя» (Фокина, 2008: 4).

Анализируя фразеологические единицы драматургии А. В. Сухово-Кобылина, мы исходим из широкого понимания фразеологии, объектом которой являются «все устойчивые сочетания слов с осложненным значением» (Кунин, 1986: 26).

Араматург занимает важное место в ряду писателей XIX в., а его творчество является важной вехой в истории русской литературы. Начало XX в. стало началом изучения как творческого наследия, так и личности А. В. Сухово-Кобылина, особенностей его биографии (А. П. Гроссман, С. Б. Рассадин, Е. С. Калмановский, В. М. Селезнев и др.). В XXI в. интерес не ослабевает. Это доказывают и публикации Н. А. Старосельской, В. Отрошенко, и репертуары театров, где пьесы драматурга пользуются огромной популярностью. Однако творческое наследие А. В. Сухово-Кобылина нуждается в дальнейшем рассмотрении в литературоведческом и лингвистическом аспектах.

Актуальность работы также обусловлена недостаточной изученностью роли фразеологии в художественной речи, в частности, в драматургии XIX в., где устойчивые обороты обладают высокой частотностью употребления, являясь ключевыми выражениями, отражающими образное видение автора.

\section{ФРАЗЕОИОГИЧЕСКИЕ ЕАИНИЦЫ В РЕЧИ ПЕРСОНАЖЕЙ ТРИАОГИИ}

Целью статьи стал анализ ФЕ в речи персонажей трилогии А. В. Сухово-Кобылина «Свадьба Кречинского» (опубл. 1856), «Аело» (1861), «Смерть Тарелкина» (1869). Аемонстрация и создание образа, естественно, происходит благодаря отбору используемых автором языковых средств. Так, рассуждая об особенностях текста Сухово-Ко- 
былина, М. Горький особенное значение придавал языку героев и указывал, что самая их речь являлась средством, при помощи которого писатель создавал социальнотипичные и в то же время ярко индивидуальные характеры. Каждый персонаж комедии Сухово-Кобылина наделен яркой, своеобразной речью, богатой стилистическими нюансами и интонациями, характеризующими социальную среду, к которой принадлежит герой, и индивидуально присущий ему психологический склад (Иотман, 1956: 498).

Предметом исследования являются фразеологические единицы в речи четырех персонажей трилогии: Расплюева, Варравина, Тарелкина, Князя. Большое количество ФЕ находим именно в речи этих героев. Автор намеренно включает в пространство художественного текста фразеологические единицы, отличающиеся оценочной характеристикой. Все персонажи - представители бюрократического аппарата, власти. Принимая во внимание биографический аспект творчества автора (непосредственные отношения с судебными чиновниками в связи с предъявленными в 1850 г. Сухово-Кобылину обвинениями в убийстве его гражданской жены), можно утверждать, что речевой портрет такого типа героя создавался с особой тщательностью. Очевиден обличительный пафос при показе представителей власти, ибо драматург не отрицает связь своих произведений с личным опытом: «Я отомстил своим врагам! Я ненавижу чиновников... Сам я никогда не служил и в департаментах являлся только просителем» (цит. по: Беляев, 1905: 110).

Так, речь Тарелкина характеризует персонажа как циничного, алчного, способного на любые поступки ради денег: «...только бы мне вот Силу да Случай, да я таким бы взяточником стал, что с мертвого снял бы шкуру...» (здесь и далее в цитатах выделено нами. - T. А.) (Сухово-Кобылин, 1989: 93); «Хочу, чтобы эта бессмертная смерть мне не стоила медной полушки - так и будет!»; «Все пойдет как по маслу, - надо только это хорошенько обставить» (там же: 143 ).

Фразеологизмы «снимать / снять (спустить) шкуру с кого» (разг. «Сурово наказывать кого-л.», см.: Мокиенко, Никитина, 2007: 754), «не стоить медной полушки» (cp. c узуальной $\Phi Е$ «Не стоит (ни) гроша (медного)»- «имеет очень малую ценность, не имеет никакой ценности, ничего не стоит» (см.: Словарь современного ... , 1954: 427), «как по маслу» («без помех, без затруднений и осложнений», см.: Фразеологический словарь ..., 1986: 238) последовательно характеризуют демонстративность в вербализации говорящим собственной циничности, жажды наживы, отсутствия каких бы то ни было нравственных и этических барьеров в достижении цели.

Фразеология маркирует в характере Тарелкина, кроме страсти к деньгам, страх бедности, осознание ненадежности своего положения среди «властителей мира сего».

Тарелкин: «Оберет он меня, каналья, оберет как липку» (Сухово-Кобылин, 1989: 93). «Обирать как мипку»- «Отбирать, отнимать все дочиста у кого-либо, грабить» (Фразеологический словарь ..., 1986: 289).

Тарелкин: «Решено!.. не хочу жить... Нужда меня заела, кредиторы истерзали, Начальство вогнало в гроб!..»; «Это ты, разбойник, вогнал меня живого в гроб!» (Сухово-Кобылин, 1989: 142).

«Нужда заела» - ср. в толковом словаре В. И. Ааля: «НужАа с костьми сгложет» (Толковый словарь ..., 1907: Стб. 1451).

«Вогнать в гроб» - прост. «Аоводить до смерти» (Фразеологический словарь ... , 1986: 57).

Образ Тарелкина гротескный. Это персонаж-маска, персонаж-оборотень, который может выдать чужую смерть за свою собственную, прикинуться вурдалаком, что- 
бы разыграть кредитора. Саркастична последняя фраза в комедии-шутке «Смерть Тарелкина», показывающая, что Тарелкин бессмертен и готов продолжать свой обман.

Тарелкин: «Господа, вам не надо ли управляющего имением?.. имею вот аттестаты (показывает аттестаты); об опытности и говорить нечего: прошел огнь и воду! Насчет честности - сами видели: за правду страдах!..» (Сухово-Кобылин, 1989: 188).

Приведенные ФЕ «пройти огонь и воду» («испытать, перенести многое», см.: Словарь современного ..., 1961: Стб. 1126) и «страдать за правду» ( «страдать за что, нести кару за вину, или гоненье за правду», см.: Толковый словарь ... , 1909: Стб. 563) создают комический эффект, их значение оказывается прямо противоположным: слова о страдании за правду становятся фарсом.

Аругой персонаж, в речи которого также актуализируются личностные качества посредством ФЕ, - исправляющий должность квартального надзирателя Расплюев. Фразеология в речи героя - активное средство трансляции неоднозначности его характера. С одной стороны, значительное количество ФЕ включают лексему «душа», что говорит о его чувствительности и даже трогательности.

Расплюев: «Тебе ведь все равно; ну что тебе мою грешную Аушу губить?» (СуховоКобылин, 1989: 43).

«Губить Аушу». Отметим, что драматург трансформирует грамматическую структуру ФЕ: если лексикография ХІХ в. фиксирует глагольный компонент в императивной форме «не загуби души», то в речи Расплюева жесткость императива снята и синтаксическая конструкция с ФЕ приобретают семантику пожелания и даже просьбы с тем же значением «погубить, убить» (Толковый словарь ..., 1903: Стб. 1001).

Расплюев: «Аолжность-то наша собачья; так вот только тем и Аушу отведешь, что закусишь этак в полной мере, да с просвещенным человеком покалякаешь» (СуховоКобылин, 1989: 153).

«Отводить душу». Фразеологизм в значении «находить для себя утешение, успокоение, разрядку в чем-либо, обычно в каком-либо занятии, деле, разговоре и т. п.» (Фразеологический словарь ... , 1986: 300) переосмысливается в тексте Сухово-Кобылина, поскольку фактически «утешением» для Расплюева является чревоугодие, что доказывает следующая цитата: «Аоложу вам - желудок мой особой конструкции: не то что волк, а волкан, то есть три волка. Он каши-то меру просит, а ему подают наперсток; - вот я и взалкал» (Сухово-Кобылин, 1989: 173-174).

С другой стороны, у Расплюева сильно желание услужить начальству и почувствовать собственную власть и превосходство над остальными. Интересно обыгрывается автором момент превращения Расплюева из мошенника ( Свадьба Кречинского») в представителя закона («Смерть Тарелкина»):

Расплюев (кладет на стол бумагу): «Великий день! <..> Все мышиные норки, все лазейки буду выворачивать наружу - я. Гм. ...а давно ли по этим лазейкам и норкам сам я свету Божьего бегал. ...вот этих петличек (указывает на свои петлички) Арожах - а таперь меня дрожать будут!..» (там же: 173).

Таким образом, индивидуально-авторскими лексико-фразеологическими средствами «выворачивать мышиные норки/лазейки» (в значении «отыскивать кого-либо или что-либо спрятанное»), «Арожать петличек» (в значении «бояться выше стоящих по рангу чиновников, представителей правоохранительных органов»), «свету божьего бегать» (в значении «прятаться, скрываться от кого-либо, чего-либо») и, наконец, «меня Арожать» (в значении «бояться, опасаться) выражена смысловая оппозиция Расплюев-мошенник - Расплюев-чиновник. По существу, именно об этом говорит и М. Е. Салтыков-Щедрин: «В судьбе Ноздревых и Расплюевых есть нечто фатально- 
двойственное. С одной стороны, в их природу так глубоко залегла потребность быть в услужении, что они готовы, в пользу „господина“, изнурять себя, рисковать своим настоящим и совсем не думать о будущем. И все это они проделывают <..> бессознательно, как бы побуждаемые какой-то фантастической палкой, которая гонит их все вперед да вперед. Но, с другой стороны, никто и не предает так свободно, как они. Изнурение - это долг; предательство - отдохновение, досуг» (Салтыков-Щедрин, 1972: 482-483).

Наиболее ярко чиновничий произвол раскрывается в драме «Аело», где символом беззакония является Максим Кузьмич Варравин. Именно он концентрирует в себе абсолютное отсутствие сострадания, бессердечность и постоянную готовность нажиться на чужих бедах. ФЕ в его речи также включают слово «душа», причем әта лексема является ключевой, однако имеет иные функции, в отличие от употребления в речи Расплюева.

Варравин: «А тут еще какое обстоятельство вышло: девочка эта, как заметно, страстно врезалась в Кречинского; ну сами судите, Ваше Сиятельство, при таких сношениях ведь девчонка этакая всю свою душонку отдаст...» (Сухово-Кобылин, 1989: 115). Не прикрытой является расчетливость, с которой Варравин планирует свой шантаж, зная о невиновности дочери Муромского: Варравин (та же игра): «Ведь я из бренного-то тела таким инструментом душу выну, что и не скрипнет...» (там же: 137).

«ОтАать богу Аушу» - устар. «Умирать» (Фразеологический словарь ..., 1986: 301).

«Вынуть Аушу» - «Измучить нравственно, истерзать, извести» (Словарь современного русского ..., 1951: Стб. 1122).

Все ФЕ с компонентом «душа» в речи Варравина имеют значение насильственного подавления, убийства. Употребление уничижительной формы «душонка» вместо «душа» подчеркивает жестокость и хладнокровность Варравина.

Вершина чиновничьего аппарата - Князь, Важное лицо, которое способствует совершению чиновничьего преступления.

Князь: «...так мы вас в бараний рог согнем; мы вот из дела-то посмотрим, что вы за лицо и как вела себя ваша дочка в этом невинном происшествии: путно или беспутно» (Сухово-Кобылин, 1989: 112).

ФЕ «в бараний рог согнуть» - «сделать покорным, смирить строгостью, притеснениями» (Словарь современного ..., 1950: Стб. 273) усиливает характеристику Князя как главного рычага страшного судебного механизма, для которого жизнь и честь человека ничего не стоят.

\section{ЗАКАЮЧЕНИЕ}

Фразеология - важнейшее средство связи человека с окружающей действительностью. Благодаря фразеологическим единицам создается мир повседневности, в котором им отводится роль социокодов. Способность таких единиц становиться кодами или знаками наиболее значима при исследовании художественного произведения, где предполагается выявление особенностей индивидуально-авторского видения мира, отбора специальных языковых и речевых средств. Фразеология и есть важнейшее средство отражения авторского мировидения и авторских нарративных стратегий. Анализ показал, что в пьесах А. В. Сухово-Кобылина использование фразеологии направлено на создание чудовищного образа судебной машины, страшной в своем беззаконии, и образов героев - механизмов, деталей, винтиков этой машины и ее жертв.

Отбираемые драматургом фразеологические единицы для создания образа Тарелкина раскрывают, с одной стороны, его алчность, цинизм, желание получить деньги 
любым способом, а с другой - всеохватывающий страх бедности. Трансформация традиционного фразеологизма становится одним из ярких и действенных средств передачи гротескности образа героя, готового выдать чужую смерть за свою собственную и произносящего при этом хвалебные речи в честь себя. Мошенник и шулер Расплюев услужлив перед более, чем он, «крупными винтиками», агрессивен и демонстративен в своей агрессии, когда чувствует власть и превосходство над людьми; но он всегда скудоумен: фразеология речи открыто, без полутонов передает эти качества. Жестокость и цинизм - семантические доминанты ФЕ в речи Варравина и Князя, которые не просто не хотят остановить систему беззакония и чиновничьего произвола, где гибнут невинные люди, но сами являются неотъемлемой ее частью. Положительных героев в «Смерти Тарелкина» нет, чиновник путем обмана другого мошенника получает бумаги с указанием его махинаций. Следовательно, обман будет продолжаться.

Как средства выражения этой идеологемы, используемые Сухово-Кобылиным фразеологические единицы преимущественно имеют негативный денотат и явно указывают на отрицательные стороны в характере персонажа: жажду наживы, расчетливость, бессердечность, жестокость, глупость, желание безраздельной власти. Высокий эмоциональный потенциал индивидуально-авторских трансформаций традиционных фразеологизмов воспринимается не только как средство обличения чиновников и всей системы судопроизводства, но и как переживание личного трагического опыта столкновения с этой системой.

\section{СПИСОК АИТЕРАТУРЫ}

Беляев, Ю. А. (1905) Мельпомена. СПб. : Тип. А. С. Суворина. 246 с.

Завьялова, Н. А. (2014) Механизмы тезаурусного расширения в русле теоретико-информационного подхода как отражение социокультурной динамики // Знание. Понимание. Умение. № 1. C. 194-204.

Кунин, А. В. (1986) Курс фразеологии современного английского языка : учеб. пособие. М. : Высшая школа. 336 с.

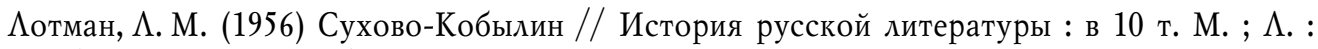
Изд-во АН СССР. Т. VIII: Аитература шестидесятых годов. Ч. 2. 512 с. С. 487-509.

Мокиенко, В. М., Никитина, Т. Г. (2007) Большой словарь русских поговорок. М. : Олма Медиа Групп. 784 с. $704 \mathrm{c}$.

Салтыков-Щедрин, М. Е. (1972) Собр. соч. : в 20 т. М. : Художественная дитература. Т. 14.

Словарь современного русского литературного языка (1950) : в 17 т. М. ; . : ИзА-во Академии наук СССР. Т. 1. XLII с., 767 стб.

Словарь современного русского литературного языка (1951) : в 17 т. М. ; А. : Изд-во Академии наук СССР. Т. 2. VIII с., 1393 стб.

Словарь современного русского литературного языка (1954) : в 17 т. М. ; $\Lambda$. : Изд-во Академии наук СССР. Т. 3. VIII с., 1339 стб.

Словарь современного русского литературного языка (1961) : в 17 т. М. ; . : Изд-во Академии наук СССР. Т. 11. IV с., 1842 стб.

Сухово-Кобылин, А. В. (1989) Картины прошедшего. А. : Наука. 360 с.

Толковый словарь живого великорусского языка (1903) : в 4 т. / В. И. Ааль. СПб. ; М. : Издание т-ва М. О. Вольфа. Т. 1. XIV с., 1744 стб., VI с.

Толковый словарь живого великорусского языка (1907) : в 4 т. / В. И. Ааль. СПб. ; М. : Издание т-ва М. О. Вольфа. Т. 3. [2] с., 1782 стб.

Толковый словарь живого великорусского языка (1909) : в 4 т. / В. И. Ааль. СПб. ; М. : Издание т-ва М. О. Вольфа. Т. 4. [4] с., 1619 стб., XVI, XII с. 
Фокина, М. А. (2008) Фразеологические единицы в повествовательном дискурсе (на материале русской художественной прозы XIX-XX веков) : автореф. дис. ... А-ра филол. наук. Орел. 50 с.

Фразеологический словарь русского языка (1986) / под ред. А. И. Молоткова. 4-е изд., стереотип. М. : Сов. Энциклопедия. 543 с.

Аата поступления: 12.02 .2015 2.

\section{PHRASEOLOGY AS A MEANS OF CHARACTER CREATION \\ IN THE DRAMA OF ALEXANDER SUKHOVO-KOBYLIN \\ T. V. LEVINOVA}

(N. P. Ogarev Mordovia State University)

Phraseology is an important means of reflecting the author's worldview and strategy. The genre of a literary work strongly influences the choice of tools for text creation. Thus, the genre of drama reveals a large layer of phraseological units that perform various functions within the text. Phraseology is also an important means of linking man to the outside world. Phraseological units act as social codes.

One of the main functions of phraseology is creating a speech characteristic and the image of the character. Large numbers of such units are found in Sukhovo-Kobylin's drama. The aim of this study is to analyze the phraseology in the speech of four characters of the dramas "The Case" ("Delo") and "Tarelkin's Death" ("Smert' Tarelkina"). It is worth noting that according to the plot, all the characters are officials, representing the government and law.

The analysis shows that the phraseological units have mostly negative connotations and denote negative sides of the characters: greed, mercenariness, heartlessness, cruelty, stupidity and lust for unbridled power. The playwright condemns the officials and the entire court system of the $19^{\text {th }}$ century Russia. The phraseological units are an effective means of expressing the author's position, becoming a symbol of the government's lawlessness.

In the context of the analysis, it is necessary to take into account some biographical data behind "The Case" and "Tarelkin's Death": Sukhovo-Kobylin had long been suspected of murder and consequently, knew the details of legal proceedings well.

High emotional potential of the transformations of ordinary phraseological units by the author not only works as a means of blaming the officials and the whole judicial system, but also becomes the manifestation of a personal tragic experience.

Studying phraseology allows the reader to identify the peculiarities of the language of a literary work, and to imagine the characters more distinctly. It also helps to conveying the author's strategy by different means and devices, especially grotesque.

Keywords: phraseology, phraseological units, speech characteristic, character, author's strategy, Russian drama, Alexander Sukhovo-Kobylin.

\section{REFERENCES}

Beliaev, Yu. D. (1905) Mel'pomena [Melpomene]. St. Petersburg, A. S. Suvorin's Printing House. 246 p. (In Russ.).

Zavyalova, N. A. (2014) Mekhanizmy tezaurusnogo rasshireniia v rusle teoretiko-informatsionnogo podkhoda kak otrazhenie sotsiokul'turnoi dinamiki [The mechanisms of thesaurus expansion within the framework of the information-theoretic approach as a reflection of socio-cultural dynamics]. Znanie. Ponimanie. Umenie, no. 1, pp. 194-204. (In Russ.).

Kunin, A. V. (1986) Kurs frazeologii sovremennogo angliiskogo iazyka [A course of phraseology of the modern English language] : A textbook. Moscow, Vysshaia Shkola Publ. 336 p. (In Russ.).

Lotman, L. M. (1956) Sukhovo-Kobylin [Sukhovo-Kobylin]. In: Istoriia russkoi literatury [The history of Russian literature]: in 10 vols.]. Moscow ; Leningrad, The Publishing House of the Academy 
of Sciences of the USSR. Vol. VIII: Literatura shestidesiatykb godov [Literature of the 1860s]. Part 2. 512 p. Pp. 487-509. (In Russ.).

Mokienko, V. M. and Nikitina, T. G. (2007) Bol'shoi slovar' russkikb pogovorok [A grand dictionary of Russian proverbs]. Moscow, Olma Media Group Publ. 784 p. (In Russ.).

Saltykov-Shchedrin, M. E. (1972) Sobranie sochinenii [Works] : in 20 vols. Moscow, Khudozhestvennaia literatura Publ. Vol. 14. 704 p. (In Russ).

Slovar' sovremennogo russkogo literaturnogo iazyka [The dictionary of the contemporary Russian literary language] (1950) : in 17 vols. Moscow ; Leningrad, Publishing House of the Academy of Sciences of the USSR. Vol. 1. XLII p., 767 columns. (In Russ.).

Slovar' sovremennogo russkogo literaturnogo iazyka [The dictionary of the contemporary Russian literary language] (1951) : in 17 vols. Moscow ; Leningrad, Publishing House of the Academy of Sciences of the USSR. Vol. 2. VIII p., 1393 columns. (In Russ.).

Slovar' sovremennogo russkogo literaturnogo iazyka [The dictionary of the contemporary Russian literary language] (1954) : in 17 vols. Moscow ; Leningrad, Publishing House of the Academy of Sciences of the USSR. Vol. 3. VIII p., 1339 columns. (In Russ.).

Slovar' sovremennogo russkogo literaturnogo iazyka [The dictionary of the contemporary Russian literary language] (1961) : in 17 vols. Moscow ; Leningrad, Publishing House of the Academy of Sciences of the USSR. Vol. 11. IV p., 1842 columns. (In Russ.).

Sukhovo-Kobylin, A. V. (1989) Kartiny prosbedshego [Pictures of the Past]. Leningrad, Nauka Publ. 360 p. (In Russ.).

Tolkovyi slovar' zhivogo velikorusskogo iazyka [Explanatory dictionary of the living great Russian language] (1903) : in 4 vols. / V. I. Dal'. Moscow ; St. Petersburg, M. O. Wolff's Partnership Publ. Vol. 1. XIV p., 1744 columns, VI p. (In Russ.).

Tolkovyi slovar' zbivogo velikorusskogo iazyka [Explanatory dictionary of the living great Russian language] (1907) : in 4 vols. / V. I. Dal'. Moscow ; St. Petersburg, M. O. Wolff's Partnership Publ. Vol. 3. [2] p., 1782 columns. (In Russ.).

Tolkovyi slovar' zhivogo velikorusskogo iazyka [Explanatory dictionary of the living great Russian language] (1909) : in 4 vols. / V. I. Dal'. Moscow ; St. Petersburg, M. O. Wolff's Partnership Publ. Vol. 4. [4] p., 1619 columns., XVI, XII p. (In Russ.).

Fokina, M. A. (2008) Frazeologicheskie edinitsy v povestvovatel' nom diskurse (na materiale russkoi kbudozhestvennoi prozy $X I X-X X$ vekov) [Phraseological units in the narrative discourse (A case study of the Russian prose fiction of the 19-20th centuries)] : diss. ... Doctor of Philology. Oryol. 50 p. (In Russ.).

Frazeologicheskii slovar' russkogo iazyka [A phraseological dictionary of the Russian language] (1986) / ed. by A. I. Molotkov. 4th edn., stereotype. Moscow, Sovetskaia Entsiklopediia Publ. 543 p. (In Russ.).

Submission date: 12.02.2015.

Цевинова Татьяна Владимировна - аспирант кафедры русского языка Мордовского государственного университета им. Н. П. Огарева. Адрес: 430005, Россия, г. Саранск, ул. Аемократическая, А. 69. Тел.: +7 (342) 29-08-35. Эл. адрес: levinovator@mail.ru. Научный руководитель А-р пед. наук, проф. В. П. Киржаева.

Levinova Tatiana Vladimirovna, Postgraduate, Department of the Russian Language, N. P. Ogarev Mordovia State University. Postal address: 69 Demokraticheskaia St., 430005 Saransk, Russian Federation. Tel.: +7 (342) 29-08-35. E-mail: levinovator@mail.ru. Research adviser: Doctor of Pedagogy, Professor V. P. Kirzhaeva. 